\title{
Discovere: An OUTREach Program at The SCHOOL OF ENGINEERING
}

\author{
Yang Cao, Seach Chyr Goh, Ahmad Rteil, Deborah Roberts, Kevin Golovin \\ School of Engineering \\ University of British Columbia \\ Email: yang.cao@ubc.ca
}

\begin{abstract}
Canadian universities are devoting more and more resources to develop $\mathrm{K}-12$ engineering education outreach programs. The School of Engineering at the University of British Columbia's Okanagan campus offers a variety of outreach and community programs for students of all ages. This paper provides details on the DiscoverE Engineering Summer Program which has been delivered since 2016. The objective of the program is to introduce students general design processes through hands-on civil, electrical, and mechanical engineering projects.

The overall goal is to foster a passion in engineering and at the same time attract students who have already had an interest in engineering and are eager to learn more about the discipline. The program is taught by faculty members and exposes students to a variety of hands-on projects in civil, electrical and mechanical engineering.

This paper will provide curriculum details for each topic and reflect on the student learning experience based on observations. Future qualitative plans on the measure of the impact of this program qualitatively will be explored.
\end{abstract}

Keywords: Outreach: Engineering: Education: DiscoverE.

\section{INTRODUCTION}

In order to attract more students into the engineering discipline, Canadian universities are devoting more and more resources to develop K-12 engineering education outreach programs. According to Actua, Canada's leading science, technology, engineering and mathematics (STEM) education outreach organization, 250,000 youth participated various programs hosted by universities and colleges across Canada in 2017 to 2018 [1]. Many of these programs are designed to promote engineering and increase engineering enrollment by attracting the high school students to study engineering at the hosting universities. Some are specifically designed for female students and indigenous students to bridge the gender disparity and boost diversity [2-4]. Other objectives of outreach programs are to provide professional development opportunities for teachers, build close relationships with local communities and enhance the undergraduate student experience [5].

The School of Engineering (SoE) at the University of British Columbia Okanagan campus was created in 2005. There has been significant growth in the last 14 years. Currently, there are a total of 1342 undergraduate students. The SoE has created a variety of outreach and community programs for students of all ages over the years, such as Geering Up Summer Program (Grades 1-7), GoEng Girl (Grades 7-9), Spring Break Camp (Grades 5-7), the Stewards in Engineering Education program (SEED) and DiscoverE Engineering Summer Program (Grades 9-12), to name a few. These programs are designed to foster skills in the applied sciences, develop a love of learning and exploration, and build teamwork capabilities.

There have been steady increases in the number of registrants for the DiscoverE program. This paper will provide curriculum details for each topic and reflect on the student learning experience based on observations. Future qualitative plans on the measure of the impact of this program qualitatively will be explored.

\section{DISCOVERE SUMMER PROGRAM}

\subsection{Structure of the Program}

The curriculum of the DiscoverE program was initially developed for a two-week summer scholars program in 2015, an initiative from the UBC Okanagan. Participants came from Brazil, Canada, Mexico, China, India, Thailand, Hong Kong, UK and the US, who are entering grades 10 and 11. The objective of the program is to introduce students to general design processes through hands-on civil, electrical, and mechanical engineering projects. Students work in teams to develop soft skills such as leadership and communication in order to emphasize the need for both within the engineering profession. A unique requirement of the program is that the curriculum be developed and delivered by professors. Four topics were taught during the two-week program, including (i) Mechanical Design using 3D Printing Technology; (2) 
Mechatronics; (3) Environment and Sustainability; and (4) Technical Communication.

Since 2016, The SOE shifted the outreach efforts to students from local communities or Okanagan valley area. The curriculum of the program was further developed to suit the needs of local students. The overall goal is still to foster a passion in engineering and at the same time attract students who have already had an interest in engineering and are eager to learn more about the discipline. The program continues to be taught by faculty members and exposes students to a variety of hands-on projects in civil, electrical and mechanical engineering. The topics of the projects include programming and control of a mobile robots; 3D modeling and printing; designing a concrete boat; designing and creating waterproof textiles and nonstick cookware; and water treatment processes. The program spreads over two weeks with students electing to participate in one or both of the weeks. The first week focuses on environmental and material engineering along with mechatronics and application design. While the second week highlights manufacturing technology, structures and materials culminating with a concrete boat competition.

\subsection{Curriculum Development}

\section{Environmental engineering}

The objectives of the environmental engineering DiscoverE experience are to orient the students to the Environmental Engineering profession through a brief lecture on the types of problems/projects that environmental engineers are involved in and to allow the students to explore methods to remove oil and suspended particles from water. We then focus in on specific water pollution problems and discuss how we can use the properties of the pollutants to remove them. The student focus is then directed specifically to oil spills and the properties of oil and water. Examples of current oil spill cleanup methods are presented. We then move to the laboratory and students design a protocol and test various materials for their potential to absorb oil from water. Students compare the materials based on the amount of oil they remove from water, the ability to recover the oil from the material and the ability to reuse the materials. Students then do a cost analysis of the use of the top two materials.

The second exercise begins with a description of suspended particles in water and how these can be removed. Students then develop their own small scale water filters by packing different arrangements of materials into a syringe and measure the turbidity of the original and treated water to determine the most effective materials to remove the particles from the water.

\section{Materials Engineering}

During the Materials Engineering days, students get a crash course in wettability and surface engineering.
Students first learn the fundamentals of materials science during a 20-minute, interactive presentation. As most high schoolers have not been exposed to this field of study before, knowing what materials science even entails is important. Following the presentation, the students are broken up into groups of $4-6$ and each starts at one of five stations. At Station 1, students identify properties of kale and spinach leaves they can view under a microscope, followed by submerging the leaves under water. The students hypothesize how the difference in observed behaviour could be caused by what they viewed under the microscope. At Station 2, students measure water contact angles on several common hydrophobic and hydrophilic surfaces, using a smartphone-based contact angle goniometer. At Station 3, the students test out hydrophobic sand and try to figure out how it keeps their fingers dry when pushed underwater. In Station 5, students learn about patterned wettability by masking a design on a plastic plate using tape. A superhydrophobic spray is then applied to the plate, followed by the removal of the mask. Finally, at Station 5, the students develop a sprayable waterproof treatment for fabric, using concepts learned from the previous three stations. The following day, the students get to test their patterned hydrophobic plates and "race" chocolate syrup down their treated fabrics, with the winning fabric repelling the confection with the least possible fouling. Last year, two students directly asked how to apply to the Materials Engineering program at UBC after completing the Materials Engineer Day.

\section{Construction Materials and Structures Engineering}

The construction materials component spans over 2 days with the aim for students to build a boat made out of cement mortar and able to float on water for at least one minute. The objectives of this component is for students to: 1) be introduced to civil engineering; 2) learn about the engineering design process; and 3) gain communications skills, all while having fun. The component is divided into four activities.

In the first activity, the students learn about civil engineering, its different disciplines and the role civil engineers play in the community. This is followed by a short presentation about concrete (how it is made and its properties). Then the students are given a tour of the Construction Materials and Structures Lab at UBC. The tour is led by a graduate student who explains the different research projects taking place in the lab and how undergraduate students could be/are involved in those projects. The tour concludes with demo tests using concrete and steel samples.

In the second activity, completed in a classroom, the students are given their project: to design and built a boat made out of cement mortar that should be able to float on water for at least one minute. They are allowed to use any shape and dimensions as long as they can build it using 300 $\mathrm{g}$ of cement. The students form their groups and start 
brainstorming their design, perform some basic calculations to make sure that their design will work and then build their moulds out of cardboard as shown in Figure 1. This process is iterative and during this time, students discuss their design with the professor and/or the teaching assistant present in the room.

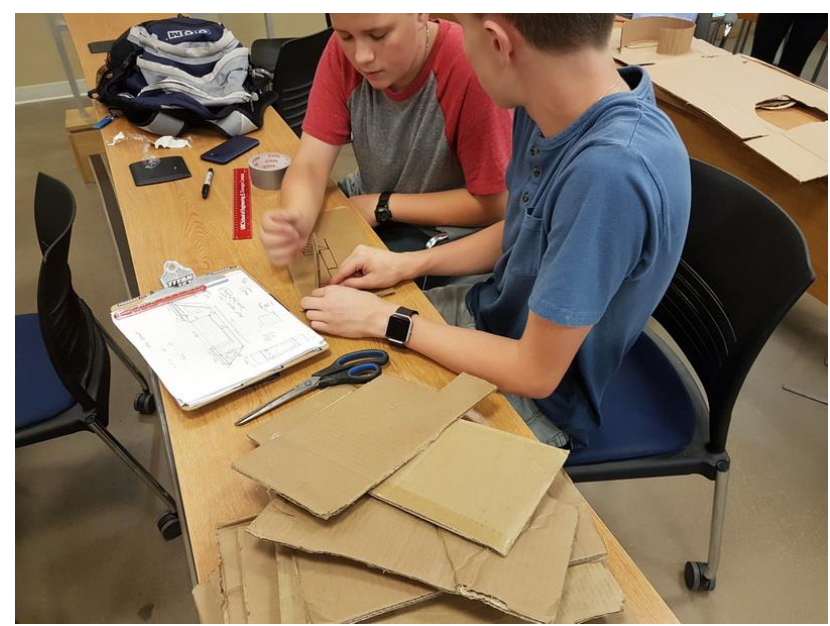

Fig. 1. Design and build mould using cardboard

The third activity is a hands-on task completed in the lab where the students mix the cement mortar and build their boats using the cardboard moulds that they made (Fig. 2 ). In some cases, groups may find that their design, while theoretically works on paper, is difficult to construct. In such cases, the students have to modify their design and their moulds.

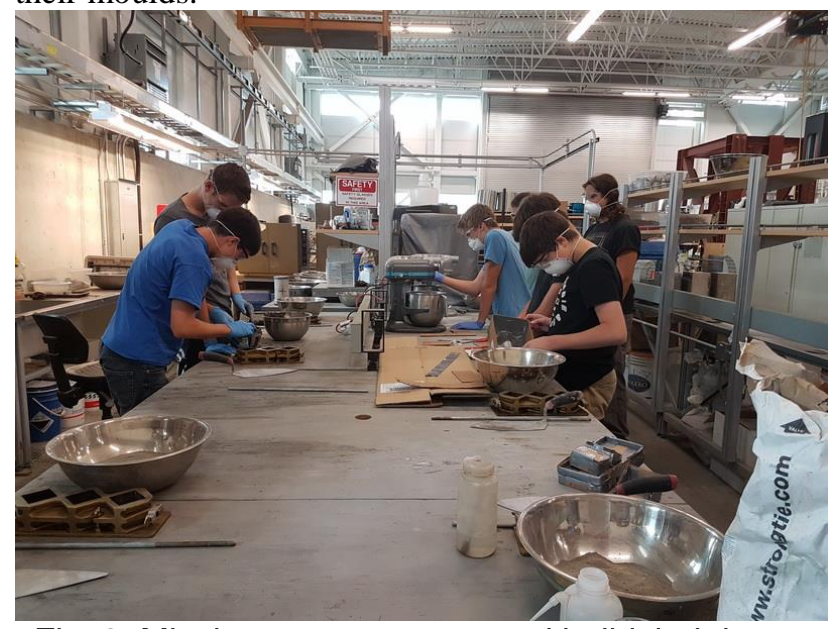

Fig. 2. Mix the cement mortar and build their boats

Two days later, the students complete their fourth activity in the lab, where they demould their boats and each group gives a 3-minute presentation discussing their design and the thought process behind it followed with 2 minutes of questions from the other groups. This is followed with each group testing its boat (Fig. 3).

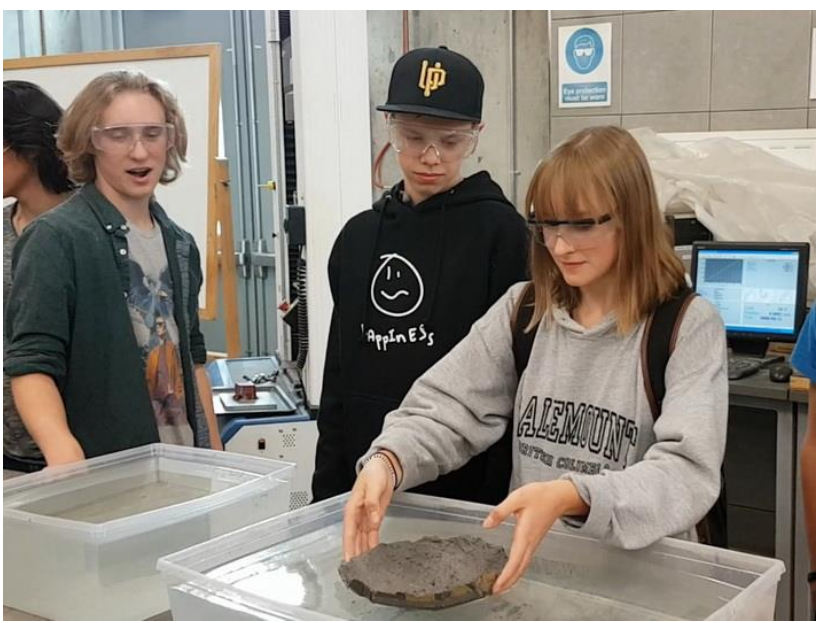

Fig. 3. Testing their boats

\section{Manufacturing Engineering}

The manufacturing engineering activity of DiscoverE is carried out over three and a half days. The objective is to let participants experience the typical engineering design, prototyping and evaluation process. The project is to design and fabricate a customised wireless mouse cover.

The first part of the activity is familiarisation with SolidWorks, a popular three-dimensional Computer Aided Design software (3D CAD). For the introductory lessons on the general understanding of $3 \mathrm{D} \mathrm{CAD}$ and the software's user interface, the instructor intentionally supplements his lesson with publicly available videos on how to use the software. This inculcates in the students the mindset of self-learning and discovery. Subsequently, the built-in tutorials provided by SolidWorks are used to further develop the students' proficiency with the software.

Halfway through the 3D CAD lessons, the students are introduced to the $3 \mathrm{D}$ printing facilities. The intention is to break the monotony of sitting in front of a computer for too many consecutive sessions and to instil some excitement with something to look forward to. Additionally, test parts are printed in various orientations which takes time while CAD lessons continue. After the parts are printed, a discussion on the merits of the various orientations is carried out, with the intention that they will make an informed choice when printing their mouse cover.

After completing the basic tutorials within SolidWorks, the design of the mouse cover begins. Students are given a pre-designed template and given suggestions on how they can modify it to their liking, such as engraving or embossing designs, adding comfort contours, etc. While the designing is carried out, pairs of students take turns to use the 3D scanner to capture a three-dimensional representation of their hand that could be inserted into the CAD file of their mouse cover to check for fit. By the end of the third day, most are satisfied with their designs and they are sent for 3D printing. The majority of students choose to print the part in the "on-edge" orientation as they are aware that it produces a less stepped surface finish. 
In the final portion of the manufacturing activity, the students post-process their 3D printed part and assemble it with the rest of the mouse and give a show and tell about their design. As part of the iterative design process, they are encouraged to talk about how they would do it differently if they had a chance to do it again.

Various projects were adopted in the past, such as cell phone case, fidget spinner, and mouse cover. Figures 4 and 5 illustrate student final work on the mouse cover project.

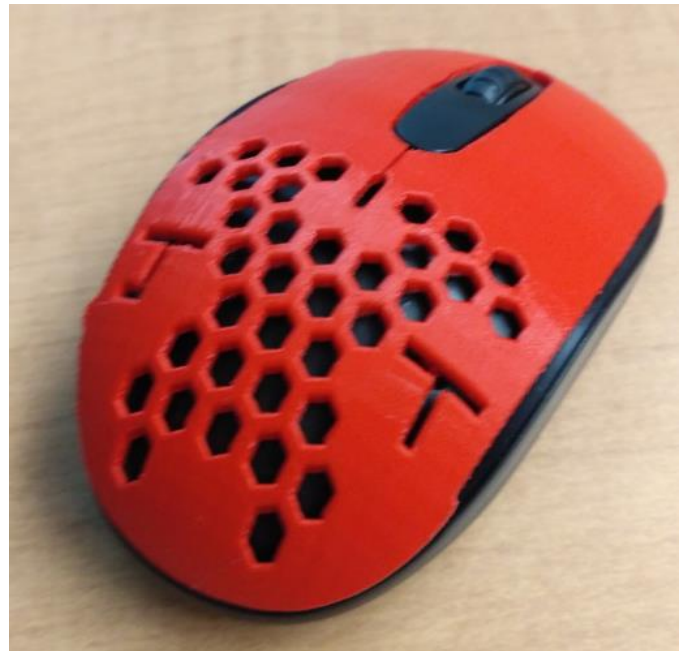

Fig. 4. Sample student work for the manufacturing project

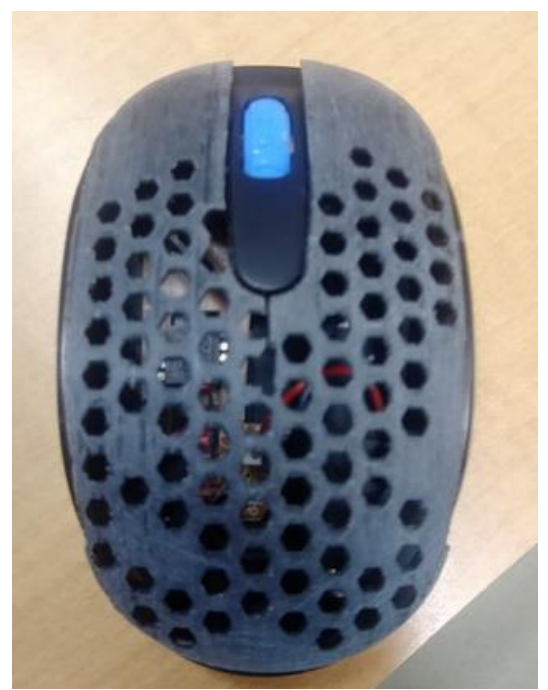

Fig. 5. Sample student work for the manufacturing project

\section{Mechatronics Engineering}

The mechatronics engineering project for DiscoverE is carried out over two and a half days. The objective is to provide students experience in programming a microcontroller to interface with various sensors and assembling an autonomous robot at the end.
A \$100 Arduino robot kit was adopted for this project. The kit comes with loose parts including Arduino UNO328, 4 geared DC motors, 4 tires, motor driver board, Arduino sensor expansion board, 1 servo motor, 1 Ultrasonic Sensor, 3 line-tracking sensors, 1 Infrared receiver sensor, 1 remote controller, 1 Bluetooth module and some other accessories such as connection wires.

The two-and-half-days project is divided into three parts. In the first part of the project, students learn how to interface the sensors with the Arduino including proper wiring of the sensors with the Arduino, how to program the Arduino using $\mathrm{C}$ to receive sensor information and how to control the motor. In the second part of the project, students learn to assemble the mobile robot and properly wire up the system. In the end, students combine the codes together and program the robot to achieve three different kinds of motion:

- autonomous motion using ultrasonic sensor by avoiding obstacles as shown in Figure 5,

- remote controlled motion using the IR receiver sensor and/or using Bluetooth module;

- autonomous line tracking motion using the line tracking sensors as shown in Figure 6.

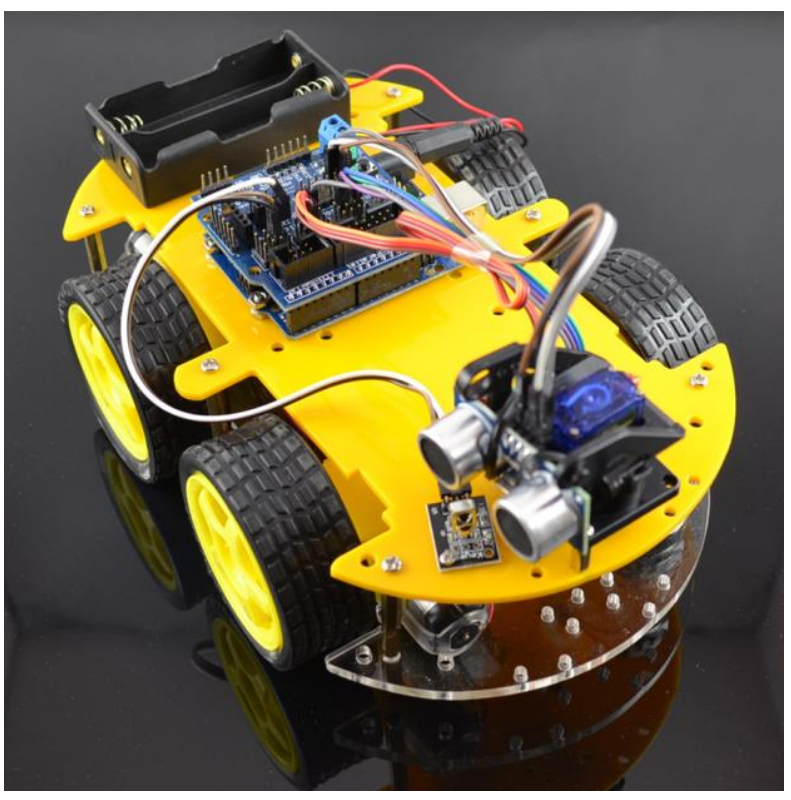

Fig. 5. Assembled mobile robot 


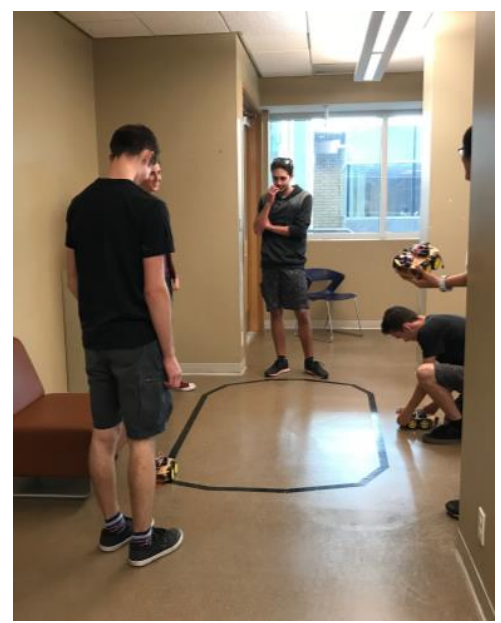

Fig. 6. Autonomous line tracking robot

\subsection{Reflection}

The DiscoverE program has been running for 4 years including the initial summer scholar program in 2015. There were 24 students enrolled for the 2015 program. The recruitment of the students was handled by UBC International Student Initiative (ISI) office. In 2016, UBC decided to discontinue the summer scholar program. There has been no shortage of summer camp for $\mathrm{K}$ to 7 students in Kelowna. However there hasn't been any professional summer program for more senior students or Grade 9-12 students. In view of this gap, the School of Engineering decided to step in and continue the program which was renamed to DiscoverE. In 2016 summer, 5 students registered for each week with total of 7 unique students (some registered for both weeks). In 2017, there were 12 and 14 students in week 1 and 2, respectively. In 2018, there were 14 and 19 students in week 1 and 2, respectively. Various marketing approaches were used. The SOE reached out to the local school district and private schools through its newsletter. Pamphlets were handed out at the SOE and APSC open house events. Advertisement was also done on Facebook. Interestingly, the program was able to attract some students from the lower mainland and the US in 2017 and 2018.

Not only is the number of registrants steadily increasing, the program has also successfully attracted students into SOE engineering programs. Three students from the 2015 cohort, 1 from the 2016 cohort and 2 from the 2017 cohort joined the SOE.

We believe that an engineering summer program developed and delivered by professors differentiates DiscoverE from a regular summer camp. It provides rigor in curriculum and ensures academic quality of the program. Many students came to the program with passion for engineering. Interacting with professors with various research backgrounds further strengthens their decision for engineering as a career path. It is also evident that this academically focused program and quality teaching presented students with a positive impression of the School of Engineering, which helped them choose SOE as their destination.

\subsection{Future Plans}

There are many ways measuring the success and impact of an outreach program [6-7]. Our objective is not only to attract students to the SOE, but also to promote engineering especially in terms of diversity and inclusivity. More focus will be on attracting female and indigenous students. The DiscoverE program is working with other outreach programs such as GoEng Girl and 30 by 30 initiative from Engineers Canada to reach this objective.

\section{CONCLUSIONS}

In this paper, we presented the structure and curriculum of an engineering summer program DiscoverE run by the School of Engineering at UBC Okanagan. The target of this program is those students who are interested in an academically focused summer program. The curriculum was designed to provide hands-on experience in various engineering projects. Registration data indicate the success of the program in terms of attracting and retaining students. This outreach program is a long-term project in order to produce a substantial impact. It is planned that the program be expanded to be more inclusive.

\section{Acknowledgements}

This DiscoverE summer program was supported by the initial funding from the School of Engineering and administrative staff support for the with recruiting and registration process.

\section{References}

[1] Preparing Canadian Youth for the Future of Work, Actua Annual Report 2017-2018, available at https://actua.ca/uploads/annual reports/Actuas 2017 2018_Annual_Report_-_Web_\%282\%29.pdf

[2] Jeanne Hubelbank, Chrysanthe Demetry, Shelley Errington Nicholson, Stephanie Blaisdell, "Long-Term Effects of A Middle School Engineering Outreach Program for Girls: A Controlled Study", Proceedings of 2007 American Society for Engineering Education Annual Conference, June 24-27, Honolulu, Hawaii.

[3] Chrysanthe Demetry, Suzanne Sontgerath, "A Middle School Engineering Outreach Program For Girls Yields STEM Undergraduates", 2017 ASEE Annual Conference \& Exposition, June 25-28, Columbus, Ohio.

[4] Andrew T. Jeffers, Angela G. Safferman, and Steven I. Safferman, "Understanding K-12 Engineering Outreach 
Programs", Journal of Professional Issues in Engineering, Education and Practice, Vol. 130, No. 2, April 1, 2004.

[5] Melissa Pickering, Emily Ryan, Kaitlyn Conroy, Brian Gravel and Merredith Portsmore, "The Benefit of Outreach to Engineering Students", Proceedings of the 2004 American Society for Engineering Education Annual Conference \& Exposition, June 20-23, Salt Lake City, Utah.

[6] M.C. Scherer and M.A. Wells, "How to Measure Success in University Led Engineering Outreach Programs for Elementary School Children", Proceedings of the 2010 Canadian Engineering Education Association, June 7-9, Queen's University, Kingston, ON, Canada.

[7] Barbara Moskal and Catherine Skokan, "Supporting the K-12 Classroom through University Outreach", Journal of Higher Education Outreach and Engagement, Vol. 15, No. 1, p. 53, 2011. 